\title{
On Forecasting for Personal Management and Development
}

\author{
Guicheng LUO ${ }^{1}$, Zhishu CUI ${ }^{2}$ \\ Xi Jinping Thoughts Research Office, Bengbu University, Bengbu, China, 233000
}

\begin{abstract}
Forecasting is a vital function of management, an irreplaceable role soothing long term fluctuation of a social system, cutting down the cost as well as the uncertainty of a project. Personal management forecasting, generally, involves social environment forecasting, personal social relationship system forecasting, personal capacity forecasting. A successful forecasting for a social system, about developing trend or a project, should be a joint effort of the environment forecasting, social relationship forecasting and the capacity forecasting, which make up a forecasting system. Researching methods include, history methods, management thoughts, long term thoughts of economics, thoughts about cycle law of a social system, mathematics methods etc. Innovations include, (1) isolating prediction as a management function from plan, (2) a general roadmap made for how to accomplish a personal management forecasting, and (3) a preliminary effort to construct a personal management system.
\end{abstract}

Keywords: forecasting function, cycle law, forecasting methods, forecasting system

\section{Introduction}

In real world, there are two major reasons for the inability of individuals, no matter how capable they are. One is environmental factors, the external environment full of uncertainty, and the other is the internal factors of the individual, the people's physiological fluctuation created by mental periodical fluctuation, and the incomplete information gotten by individual. Therefore, the Chinese prefer to plan in advance, which implies to plan and prepare early before doing significant matter.

One of the important purposes of personal management (PM) is to avoid risks and uncertainties, to ensure survival and development. Therefore, effective management forecast is of great significance. Modern management, forecasting is an inevitable procedure and routine content.

Chinese people have been engaged in management forecast in very early era. Bible of Change is one of the earliest classics of management forecast in human society (photo source: www.baidu.com). Most of the ancient Chinese military statesmen were masters of forecast. During Chinese Spring-Autumn period, Guan Zhong of Qi Kingdom explicitly told the Duke of Qi Huan, Yi Ya and Shu Diao should not be designated with crucial mission. Bai Lixi, Jian Shu of Qin Kingdom forecasted successfully that Jin Kingdom would set an ambush at Xiaoshan before Qin Mugong sent troops to attack Zheng Kingdom. In Chinese Three Kingdoms period, Zhuge Liang predicted three-thirds of the world without stepping out of his grass cabine. Sun Zi Military Arts, popular all over the world now days, can also be regarded as the earliest classics of military forecast, in which the thought of heaven climate, earth situation and human as a whole unity are still valuable reference for modern forecast management.

Modern management forecasting has become a mature science, forecast technology is well developed, the computer forecast system is widely used in economic forecast, weather forecast, military forecast. So far, no research has been found on personal management forecast by employing contemporary forecast science. There could be two reasons: firstly, personal management is an interdiscipline, just starting short time ago, secondly, the historical data of personal development is difficult to collect, which makes it hard to set up a PM forecasting system.

\section{Categories of PM forecasting}

Nevertheless, we could make tries and efforts to predict the development of human life. Any social system, management is implemented under the interaction of the system with the environment. Therefore, the prediction can be sorted into environmental prediction and system capacity prediction. If from the stages of life development, prediction could be categorized into long term prediction, short term prediction and project prediction, or, general trend forecast, specific point forecast. From forecast methods, it could be divided into qualitative prediction and quantitative prediction.

\section{PM forecast principles}

General management principles are applicable to the management forecasting function, but, because of the special vital position of the management forecasting function, the principle of management forecasting is restated here.

\subsection{Systematic principle}

Systematic principle is the most important principle of all management work, also the most important principle of forecast. The system involves the whole unity consisting of environment and related individuals or organizations within. "The person not reckoning the overall situation could not be capable enough to plan a part" (Xi Jinping, 2014), the overall situation conception, the big picture consciousness decides the management thoughts, the management thoughts determines the management efficiency, e.g. macro in mind, micro in hand.

\section{Volume 8 Issue 9, September 2019}

\section{www.ijsr.net}




\section{International Journal of Science and Research (IJSR) \\ ISSN: 2319-7064}

ResearchGate Impact Factor (2018): 0.28 | SJIF (2018): 7.426

\subsection{Information principle}

The information principle is also very important, sometimes, which is called the first important principle. The first importance here does not imply that information is really first, but, all management judgments are based on the information obtained, 'no investigation, no statements'. Information and intelligence work is the foundation of all management work. Management prediction is established upon historical as well as realistic information. Common organizations have intelligence centers or agencies related to intelligence work. Information may be the real information directly reflecting the object, or the false information distorting the object.

\subsection{Human hearts principle}

Or social principle, humanism principle, human nature principle. A lot of forecasting, fulfilled under certain conditions, could not be accomplished with forecasting systems or mathematical models, for there is no data available. So, the best way is to analyze people's heart and human nature. In Chinese Three Kingdoms period, Zhuge Liang slaughtered Wei Yan after his death, whose conclusion came from his study upon Wei Yan's character. Many predictions would not require mathematical models as well as computer forecasting systems at all, heart-to-heart, thorough perception into human nature will uncover the future. Therefore, Human hearts Principle is a very important principle for management prediction.

\subsection{Principle of one unity for heaven, earth and human}

Standard management science does not involve this principle, while, it is also a vital principle. The former three principles are the application of the truth from the known science. In real world, there is still a lot of scientific knowledge unknown to human beings, and lots of things cannot be explained by existing scientific knowledge, which does not imply they are not truth or do not exist. Many religious phenomena are related to the unknown truth. Heaven, earth and human are a whole system of energy cycles, interacting with and affecting each other. Intuition could be the result of the interaction of various energy elements in the world. Yan Yaojun put forward the method of precursory index system for social prediction. We feeling something wrong in the whole atmosphere, perhaps the energy of disadvantageous factors is functioning. Of course, Our feeling good could not ensures a promising situation. In the military contest, some atmosphere is created deception, TV story Zhu Yuanzhang, Prime Minister Hu Weiyong created rumour, delicious wine gushing out of well, in order to trap and murder Zhu Yuanzhang.

\subsection{Dynamic principle}

In a complex environment, many forecasting conclusions are probabilistic, as leads to the monitoring and judgment on the entire situation accompanying the whole management process. So, the intelligence department needs to adjust its forecasting conclusions with the change of the situation. Enterprises, military organizations, and state economic institutions confronting complicated environments, their intelligence agencies will set up full-time forecasters. Individuals in a highly uncertain environment need to make forecasting periodically.

\section{Characteristics of PM forecasting}

'Two ears not listening to things outside the window, only read saints', such environment becomes rarer and rarer in contemporary society, also scarce in the entire life career. A pluralistic society requires individuals and organizations to be an open system continuously exchanging information and energy with the external environment, to make the whole management system ready to answer the interruption from the environment. Generally, conception of self-closure will increase the collapse risk of individuals and organizations. Do frequent conflicts in Islam world have ties with its closed tradition? Therefore, multiple societies have hiked the weight of management forecasts. Because of the irreplaceable significance of forecasting in management, it is isolated from the planning function and studied separately. So, management has five functions (figure 1), e.g., forecasting, planning, organizing, coordinating and controlling.

Management forecasting has two main features: (1) it is the foundation of all management work and the first procedure of management program. It is necessary to carry out forecasting work to various degree before the start of any management work; (2) as a whole, It is the routine management work, vital, directly affecting the efficiency of management, connected to the fate and future of individual or organization, running through the whole management process.

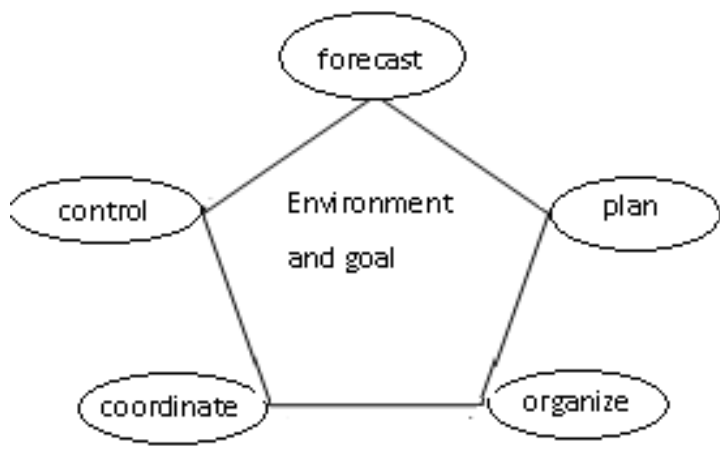

Figure 1: Relationship between management techniques and object

\section{PM forecasting process}

A general management forecasting program runs as following:

(1) Information collecting

That is to collect as much information as possible related to the whole situation, the information should be inclusive. If a significant military confrontation, it should cover not only conventional information, but also unconventional

\section{Volume 8 Issue 9, September 2019}




\section{International Journal of Science and Research (IJSR) \\ ISSN: 2319-7064}

ResearchGate Impact Factor (2018): 0.28 | SJIF (2018): 7.426

information, involving gossips. Ancient Chinese thoughts, heaven and human are inter-telepathic, heaven, earth and human are one whole unity. Ancient Chinese military and political prediction employed celestial phenomena and nursery rhymes, which is worthy of further study by contemporary scientists.

(2) Information analysis and research

Synthesizing all aspects of information, analyze it, removing distorted information and irrelevant information.

(3) Make conclusions on the judgment for future

"Hearing all sides creates brightness, bias results in darkness", judgment based on a single information could be risky. Steps of personal management prediction are: (1) environment prediction; (2) prediction of personal social relationship system; (3) prediction of individual ability; (4) planning and decision making. Environmental prediction, individual social system prediction and individual ability prediction are one whole unit, base planning and decision making, serving for the accurate judgment upon the situation.

\section{Environment Forecasting}

"Attach great importance to investigation and research", any systematic prediction, environment prediction is the most important as well as one of the toughest work. The quality of environment directly affects the quality of prediction. The $\mathrm{PM}$ environment prediction includes,

\subsection{Value, moral environment forecasting}

Value, benefit and ability are three variables influencing people's decision making. Value prediction is an important part of social prediction. Luo Guicheng, Fei Ruibo, Chen Jiyin sorted values into personal values, group values. In a general environment, both individual values and group values are rigid, hard to change in a short term, especially the concept of adults and group values. Group values have greater rigidity, stability. 'Mobilization of the masses' is not easy.

Research by Luo Guicheng, Fei Ruibo and Chen Jiyin, after entering college, personal values will undergo the first major change. From college graduation to 30 years old or so, Personal values undergo the 2nd significant change, then into the adjustment period. About 45 years old, personal values stabilize comprehensively, that is, "men more than 40 with no bewilderment." Their viewpoints, there are six factors determining the difference of personal values: family education, school education, regional customs, political factors, personal experience, professional factors. As a whole, 'A travel more than 500 kilometers, equivalent to reading more than 10 thousand volumes', the change of educational factors and external environment would be liable to modify personal concept. Deng Xiaoping's 1978 reform was more or less related to his trip to U.S.. The objective world is the biggest lecture hall for truth. According to the research above, we can roughly judge individual values by the six factors. Particular statement, for individuals with religious experience, religious beliefs have greater influence on their minds, and most religious believers are more trustworthy.

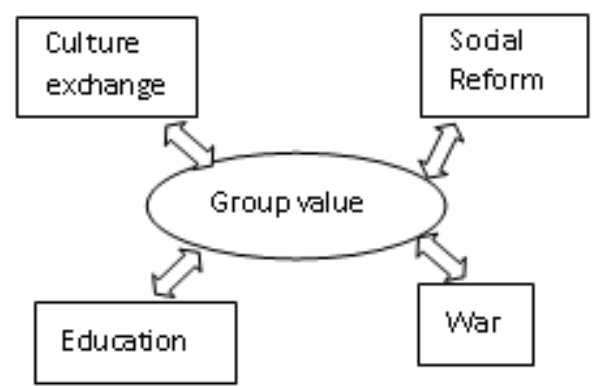

Figure 2: Factors changing the value of a group

There are four major factors leading to the change of group values (fig. 2), (1) cultural exchanges among different regions of the world, such as Tang Sanzang's pursuing Sutras, Jianzhen's voyage to Japan, Marco Polo's trip to China and Columbus' discovery of the new continent. (2) Political and economic reforms, such as Shang Yang's reform, Deng Xiaoping's reform. After Deng Xiaoping's reform, the Chinese people's minds have undergone revolutionary changes. (3) Education. Religious cause, school education, community education and family education will all shape and change social group values. (4) War. In modern history, aggression wars against China by western countries have played a positive role in Chinese political and cultural progress. Based on these four factors, we can predict some future changes in a country or region.

The sociality is the first attribute of human being, an individual must trade ideas or materials with social groups as a whole. Personal values will interact with group values. There are six major factors to determine personal values. "People's hearts are separated from their shells", people always have different ideas. Differences on values are the important reason of social conflicts and social risks. A society has diversified groups with various belief, different people have different inner concepts. In general, people in the depths of the mountains and ditches stress more justice and integrity, people in the cities could pay more concern to benefits. Religious people, charitable organizations, political parties, government and institutions, people in colleges would have more sense of morality. People in vehicle or railway stations, commercial zones, entertainment districts could be more snobbish, and youth tend to be impulsive, creating aggressive behaviors. The middle-aged and the elderly would be milder. There are also extreme groups, such as official agents, members of underground social organizations, who are special at deception and disguise for their professional capability, prone to attack, they are high risk social groups. So, common people should be more cautious about what they say and do in society. Avoiding and handling conflicts properly are important functions of value prediction. The main purpose of the short-term value prediction is to compare the value differences between individuals and groups, as well as those among individuals, to determine the behavior choices, shunning off conflicts. 


\section{International Journal of Science and Research (IJSR) \\ ISSN: 2319-7064}

ResearchGate Impact Factor (2018): 0.28 | SJIF (2018): 7.426

The main purpose of long-term value prediction is to research the value as a factor affecting the long term development curve of individuals, to provide a reference for the reform of individual values.

Individuals entering North Korea, China, U.S. and the Arab world differently influenced by politics and religion, should have different choices of behavior. Moreover, different regions of the same country have different values. People's concepts vary far differently along with western China, eastern China, Chinese rural areas and urban areas. During the implementation of regional management decisions, value alerting in advance is necessary.

The analysis of values can help to judge whether the individual would encounter major setbacks after entering a specific regional environment, the possibility of conflict among individuals, the possibility of conflicts among countries. The greater the degree of openness among countries or regions, the more communication, the less rigid the social members' values, the greater the elasticity, the less the possibility of conflicts would happen among individuals for the value differences.

Value change and social change have relations mutually reinforcing each other. The change of value is usually the omen of social change, a significant value change will often ignite a reform. In Sun Zhongshan's revolution, Deng Xiaoping's reform or Xi Jinping's Reform, the change of inner values happened at first. The change of individual values often connotes the change of the individual behavior choice in the future. In the social communication, people's "throw a stone to try the way", "induce one's voices" is mainly to test the other party's attitude, to provide references for decision-making. With the deepening of social change progress, social reform will push forward value change in turn, deepening the value reform. Today's China, people's minds have changed greatly, non-comparable to those before reform, which is the inevitable end of deepening reform. Around 2010, there were "nude beauty banquets" in China, which were unimaginable before Deng Xiaoping's reform. The reform and opening up profoundly impacted the traditional ethics of Chinese people. The concept of the Chinese people has undergone a ground-shaking change. After $\mathrm{CPC}$ with $\mathrm{Xi}$ Jinping as the core promoted Four Comprehensive Strategies, social values regained its simplicity as well as modesty.

The degree of value change is an important factor to predict the future trend of individual or society.

\subsection{Forecasting for globe and domestic political situation}

Prediction on the long-term fluctuation of international as well as domestic political situation serves to forecasting the long-term fluctuation of individual development, providing information reference for personal strategic management in the future.
5.2.1 Cycle law and the long term curve fluctuation of a social system

The periodic law is an important law for the development and change of all matters, which could also be employed to forecast the international political situation. The cycles researched by the globe society cover the economic cycle, the institutional reform cycle, the war cycle, and the periodic law of history.

Schumpeter business cycle theories, 40 months for a short cycle, 9-10 years for the medium cycle, 48-60 years for a long cycle. According to Schumpeter innovation theories, the cyclical change of social innovation power is an important reason for the periodic fluctuation of economy. Hao Hongbin sorted the war cycle of the international society into three stages: the first cycle was 1865-1917, the second cycle 1917-1961, the 3rd cycle 1961-1991. Hao Hongbin's sight, the vital cause for the formation of the world war cycle is technology progress. Hao Hongbin's war cycle is approximately the same as Schumpeter's long economy cycle. War will surely lead to economic fluctuations, economic fluctuations would cause war, both are by no coincidence.

During Chinese Spring-Autumn period, 395 wars happened, and 230 wars took place during the War States period. The Spring-Autumn\& War States period began at 770 BC, ended at $221 \mathrm{BC}$. In the long history of 549 years, the 'international society' has an average of about 1.1384 wars per year, or one war each 0.878 years. Modern international community, by rough calculation, 1953-1999, there were 25 major wars, an average of about a war in every 1.84 years. Compared with the Spring-Autumn and War States period of China, the civilization of human society is improved and the cycle of war is prolonged, but the threat of war in international society still exists.

Around 1708, the war against Russia launched by Charles XII of the Ottoman Empire failed. Around 1812, the war against Russia launched by Napoleon failed. World War II, the early 1940s, Hitler launched the war against Russia failed. In modern world, rationality grows together with technology progress. According to war cycle against Russia in history, it is estimated that the $3^{\text {rd }}$ World War would be around 2020, or even the middle and later part of this century, that is, around 2060 (about 20 years of error). This period, if not wrongly gauged, it would be in the period when new international forces, such as China, Russia, India, Brazil, in transition with globe old powers, Europe and U.S etc.. According to Schumpeter's long-term economy cycle, the next long-wave optimum of Chinese economy appears around 2040. It would be the theoretical proof of Lin Yifu as well as Zheng Lixin's sight that there would be still about 20 years of high-speed growth in China, on the basis of which, after 2040 or so, China's economy began to enter a long-term adjustment, the overall growth rate will slow down significantly, and may encounter the 'overall saturation problem', such as current U.S., Western Europe, Japan and other developed countries. The reform cycle of Chinese institution is about 30 years, on this gauge, around 


\section{International Journal of Science and Research (IJSR) \\ ISSN: 2319-7064}

ResearchGate Impact Factor (2018): 0.28 | SJIF (2018): 7.426

2040, China will initiate the $3^{\text {rd }}$ wave reform to deal with the 'overall saturation crisis'. Around 2040, if Taiwan not reunified, the Taiwan issue would run into the other direction. Around 2060 (20 years error), without reunification, Taiwan might declare independence, which is consistent with the prediction for the possible outbreak of the 3rd World War.

In addition to the economy cycle, war cycle, institution reform cycle, the human history also had the feudal dynasty transition cycle, in China, which is called the historical periodic law. In China, the complete sense of feudal society began at Qin Dynasty from 221 B.C., and died at Qing Dynasty in 1912, spanning 2133 years, running across 10 historical periods. The Three Kingdoms, the Southern and Northern dynasties after Han Dynasty, were regarded as divided, and the time span was 369 years. After Tang Dynasty, the Five Dynasties and Ten Kingdoms were divided in general, with a time span of 53 years. These 10 historical periods of Chinese feudal society averaged 213.3 years per period, the two split periods deducted, 2133$(369+53)=1711$, and the average life span of the eight feudal dynasties was 213.875 years. The longest life span was 422 years (202 BC-220 AD) of Han Dynasty, followed by Song Dynasty 369 years (960-1279), Tang Dynasty 289 years (618-907), the Ming Dynasty 276 years (1368-1644) and the Qing Dynasty 276 years (1636-1912). The shortest life span was 14 years of Qin Dynasty (221 BC-207 BC), followed by 37 years of Sui Dynasty (581-618 AD), and 97 years of Yuan Dynasty (1271-1368 AD). From the above facts, conclusions about the periodic law of Chinese history could be made, (1) the more severe the violation of civil rights and people's livelihood, the shorter the life cycle of the related dynasty, no matter the violation comes from a widespread institutionalized official violence, or from large scale official corruption, such as Qin, Sui and Yuan dynasty. (2) An invasion of international forces will accelerate the end or collapse of a corrupt power system, such as Song, Ming and Qing dynasty. (3) Individual or partial civil anger is not powerful enough to overturn a dynasty. The end of the dynasty comes from the long accumulation and upsurge of widespread civil anger, or the invasion from external forces of the social system, or the combination of both. There is only one fundamental reason for the end of the dynasty, official corruption or other causes for the depression or inadequacies of authority capacity. (4) Without considering a reasonable legal system, there is little significance to compare democracy with despotism. The most essential matter is whether they can guarantee the development of people's livelihood and the national capacity. The most radically, whether they can ensure and develop the material civilization as well as the spiritual civilization, whether there is a powerful legal system to offer safety. The United States and China in the early 21st Century have shown that democracy or centralization is not the fundamental cause of the rise or fall of a social system, while, whether it can ensure the development of material civilization as well as spiritual civilization is 'the invisible hand' behind the social change. Unreasonable design, no legal protection, the two civilizations not guaranteed, no matter democracy or autocracy, both would not last. Taking a Chinese slavery Dynasty, Zhou, as an example, the democracy of the Zhou Dynasty failed to have a healthy legal system, as a result, it became laissez-faire, impairing the national capacity, causing its perishing eventually. The dictatorship of Qin Dynasty abused national violence and endangered civil rights as well as people's livelihood, which created widespread rebelling, resulted in its quick collapse. (5) Suitable institutional change helps to prolong the life cycle of a social system. Han Dynasty, Tang Dynasty, Song Dynasty, Ming Dynasty, Qing Dynasty all carried out large-scale institutional reform. To sum up, there are three factors that determine the life cycle of a feudal dynasty social system, civil rights and people's livelihood, internal government capacity (including institutional reform), external aggressions.

Above studies, economy cycles and institutional cycles usually function in a stable social system, which are subordinate to dynasty transition cycles. The annual solar energy supply available to the Earth can be regarded as a constant as a whole. The indefinite pursuit of growth by a social system violates the law of conservation of energy. In other words, economy periodic fluctuation is normal in human society, which has nothing to do with institutional design. The frequency of economy cycles is related to the quality of institutional design, or to the energy utilization efficiency of the institutional system. Further, economy cyclical fluctuations are not the fundamental cause for a 'dynasty' transition, or triggers at most. War cycles are highly correlated with dynasty transition cycles. War outbreaks originate from internal conflicts or external conflicts of a social system.

Compared with history, the efficiency of Chinese social system is unprecedented, compared with U.S. and Western Europe, there could be room for improvement. The United States has too much democracy, so it should make adjustments to enforce the centralization of power, for example, cutting down the power of parliament, expanding the power of government, constraining the degeneration of human nature by excessive freedom, reforming the policy of large-scale fiscal deficit, stopping the strategy of oversea military expansion, and so forth. China system might be fine-tuned to reinforce democracy, for example, to consider the expansion of local voting rights in ethnic minority regions, the enforcement of Chinese language education in ethnic minority regions. Establish the auditing system upon state heads as well as local political heads, to consider the unleashing for religious rights of CPC members. Objectively, if not reformed, the stability of U.S. or Western European social system might be higher than current China, in other words, the sustainability of U.S. or Western European social system could be a little healthier. Taking 30 years as an institution reform cycle, Chinese Dream fulfillment could have to go through at least 2 to 3 institutional reform cycles. According to the periodic law of history, the stability of North Korea social system could be the worst. If not reformed, there might be a violence revolution in the next 5 to 30 years, which would affect the situation on the Korean 


\section{International Journal of Science and Research (IJSR) \\ ISSN: 2319-7064}

ResearchGate Impact Factor (2018): 0.28 | SJIF (2018): 7.426

peninsula, then Northeast Asia and China. It must be pointed out that, CPC with $\mathrm{Xi}$ Jinping as the core, "comprehensively deepening reform" strategies have achieved real effects, and the spiritual wealth Xi Jinping Thoughts have been employed as the engine of the China social system. Two civilizations have been made qualitative breakthroughs. The endogenous ability of the whole social system has leaped upon a new level. China globe reputation has been enhanced significantly. The success of Xi Jinping Reform in comparison to the crisis of U.S. democracy in the same period has manifested once again that the construction of Two Civilizations is the key to the survival and development of a social system, and democracy or centralization is not the fundamental reason for the prosperity or decline of social systems. Surely, extreme things must be avoided, extreme democracy or extreme centralization will definitely create harm, which human history has explicitly proven.

Therefore, to forecast a social system, the prediction for the situation of Two Civilizations and the endogenous ability to guarantee the development of Two Civilizations in a social system should be regarded as the most important macroscopic index.

What is the stability of the international social system based upon UN? The UN international system is equivalent to the Zhou Dynasty in Spring-Autumn Period and War States Period of Chinese history, its influence on the international community quite limited. However, current hearts of the international community are generally more civilized than Spring-Autumn and War States period of China. Despite the danger of the third World War, the central authority of the $\mathrm{UN}$ is likely to be reinforced in the future half century. So, the UN international system is relatively stable. The disintegration of the UN international system is likely to be accompanied by the outbreak of the third World War. It took 549 years to unify the Spring-Autumn and War States period. If current international social system is to establish a real central authority, it will have to go through two hundred years or even longer historical periods.

In the future, the 2 to 3 cycles of institutional change in China are actually the long-term fluctuation trend of Chinese social system. In connection with the cooperation and conflicts of major countries in the globe society, personal development has opportunities as well as challenges.

\subsubsection{Analysis on international conflicts and purposes of big powers}

The whole world is an interactive energy field, and the individual is a part of it. The political turmoil in Syria since 2012, the armed conflicts in Russia, Ukraine in 2013, 2014, these international political events, ostensibly, have nothing to do with common people. For in-depth study, behind the political turmoil in Syria, the armed conflict between Russia and Ukraine, it is not a simple regional or religious contradiction. They are all associated with the conflicts of values, interests, or the contradiction among Russia and
U.S., Western Europe, these several major political powers in the world. If world major forces have mishandled these conflicts, they are likely to evolve into world wars. They are, of course, linked to the Diaoyu Islands disputes between China and Japan, the Taiwan Strait relationship, the South China Sea disputes and the situation on Korean Peninsula. China, Russia and other countries are traditional international political interest group. U.S., Western Europe, Japan etc. are another political interest group. Although there are historical reasons for international conflicts in recent years, in fact, most of them are connected with conflicts of values, interests between the two major globe groups. If the political turmoil in Syria and the intensification of tensions between Russia and Ukraine ignites an intensification of Chinese coastal disputes, the result will not be anything not associated with the fate of our common people.

In human history, a civilization is fragile if it is not protected by a powerful institution system. During Spring-Autumn period, several overlords appeared in China, many of whom tried to establish a fair and just international political order, but none of them could stand the test of time. Hundreds of years later, the Strong Qin put forward violence revolution, established a new civilization, the Great Qin Empire. The current international community is very similar to Chinese Spring-Autumn and War States period, and UN also seems analogue to central Zhou dynasty without authentic authority. From this observation, there are war risks in the international society in the future, which is consistent with the argument of the previous war cycles.

The international political situation will affect the domestic political situation, and the macro political situation will affect the quality of the entire social environment, affect our near-term and long-term operation state. Businessmen will not make long-term investments in a country with war prospects, nor will tourists travel to a region where war is likely to outbreak.

To study the international political situation, we should grasp the long-term and short-term intention of the leading country and the change of its overall national capacity. Study of the intentions of the leading country, crucially, (1) national values, (2) national long-term strategy, (3) historical decision-making habits, (4) the preference of current main leaders, (5) domestic economic situation, (6) the situation of allies, (7) the situation of competitors, (8) the influence of domestic interest groups on national decision-making (Table 1). U.S. is the dominant power in the world for nearly half a century. It has tried to establish a democratic and just world, and its armed forces have been deployed all over the world. In recent years, the U.S. economy has become fully saturated, its economy has slowed down. China, Russia, India, Brazil, South Africa and other countries have risen, and U.S. has become relatively less influential internationally. In the next half century, China is likely to overtake U.S. as the world most influential power. However, Chinese internal institutional pressure, internal struggles of different interest groups, territorial 


\section{International Journal of Science and Research (IJSR) \\ ISSN: 2319-7064}

ResearchGate Impact Factor (2018): 0.28 | SJIF (2018): 7.426

disputes, ethnic and religious contradictions are important unfavorable factors, which might lead to the systematic collapse of China. By contrast, the internal contradictions in U.S. are not so severe. The previous study, judging from the hundreds of years of institutional efficiency competition, if China does not eliminate hidden dangers, it could not really outrun U.S.

Table 1: Analysis on the purpose of the dominant power as well as that of the domestic

\begin{tabular}{|c|c|c|}
\hline & $\begin{array}{c}\text { U.S. } \\
\text { purposes }\end{array}$ & $\begin{array}{c}\text { Chinese } \\
\text { purposes }\end{array}$ \\
\hline National value & & \\
\hline National long term strategy & & \\
\hline Decision-making habit in history & & \\
\hline Preferences of incumbent main leaders & & \\
\hline Domestic economy situation & & \\
\hline Allies situation & & \\
\hline Opponents' situation & & \\
\hline Influences from internal benefit groups & & \\
\hline
\end{tabular}

In addition to doing his own work well, a capable person will have his rest energy to express his own position, publicize his own values, and assist or interfere with the people around him; a weak person will be busy with his own internal affairs, less caring for others. The same to a country, powerful nations have more capacity and willingness to speak in the international community. Table 1,

Table 1 (A): The system of personal social relation

\begin{tabular}{|c|c|c|}
\hline \multirow{6}{*}{ Positive factors } & \multirow{3}{*}{$\begin{array}{l}\text { Explicit } \\
\text { factors }\end{array}$} & Leaders, colleagues \\
\hline & & Relatives, teachers \\
\hline & & Classmates, friends \\
\hline & \multirow{3}{*}{$\begin{array}{l}\text { Non-explicit } \\
\text { factors }\end{array}$} & Leaders, colleagues \\
\hline & & Relatives, teachers \\
\hline & & Classmates, friends \\
\hline \multirow{6}{*}{ Negative factors } & \multirow{3}{*}{$\begin{array}{l}\text { Explicit } \\
\text { factors }\end{array}$} & Leaders, colleagues \\
\hline & & Relatives, teachers \\
\hline & & Classmates, friends \\
\hline & \multirow{3}{*}{$\begin{array}{l}\text { Non-explicit } \\
\text { factors }\end{array}$} & Leaders, colleagues \\
\hline & & Relatives, teachers \\
\hline & & Classmates, friends \\
\hline $\begin{array}{c}\text { Neutral factors } \\
\text { (non-related factors) }\end{array}$ & & \\
\hline
\end{tabular}

Data source: Luo Guicheng, Luo Rundong. A systematic analysis on the system of personal social relations [OL]. www.paper.edu.cn. 2008 / 07: 2-3

Luo Guicheng, Luo Rundong (2008) made efforts to predict the system of personal social relations (Table 1A). They set up the system of personal social relations by factor analysis. The positive factors play a positive role upon the subject, the negative factors play a negative role upon the subject, the strong are explicit factors, and the weak are non-explicit factors. Those outside the system of individual social relations are non-related factors. They think that when the positive factor of the personal social relationship system is more important than the negative factor, the personal development will rise, on the contrary, the personal development will fall. With the running of time and the the choice of great powers behavior is mainly influenced by national strategic demands, external environment, internal power struggle, then they can spread their own values and dominate the international order. In short, it is important to study the international situation and grasp the sentiment of major countries. Just as the common society, the big brother's words have heavy weight. In the international community, the mood of the world major countries can stir up political turmoil as well as eliminate political turmoil.

2014-2016, the intensification of Chinese coastal territorial disputes was largely influenced by the U.S. "Return to Asia-Pacific" strategy, and the conflict between Russia and Ukraine was also a corollary of NATO's eastward expansion. With historical experience, in the next half century, the international community has entered a transition era in which U.S., NATO and other old hegemony power exchange roles with China, Russia and other new powers, as is an era of greater risk of war for the international community.

Modern economy forecasting system has been well developed, there is no special research for environmental and economic situation prediction in our research. It should be pointed out that values, politics and economy belong to the social system, influencing each other. To forecast economy without considering the political situation, the conclusion would deviate far from the reality.

change of environment, the properties of positive factor and negative factor may develop and change, which leads to the positive or negative evolution of individual social relation system. Their theory is applied to the international espionage struggle. The behavior utilizing the member of the social relation system of the opponent, is called social relation data pollution. According to their research, the future of individual social relationship system can be forecasted by predicting the change of individual social relationship factors, combined with the change of social environment. During Chinese Three Kingdoms period, if Shu Kingdom could predict the impact by the death of Zhuge Liang, a positive explicit factor, upon the national situation, Shu might make more long-term strategic preparations, such as human resources reserve, economy reserve, strategic adjustment of big country relations, and so forth.

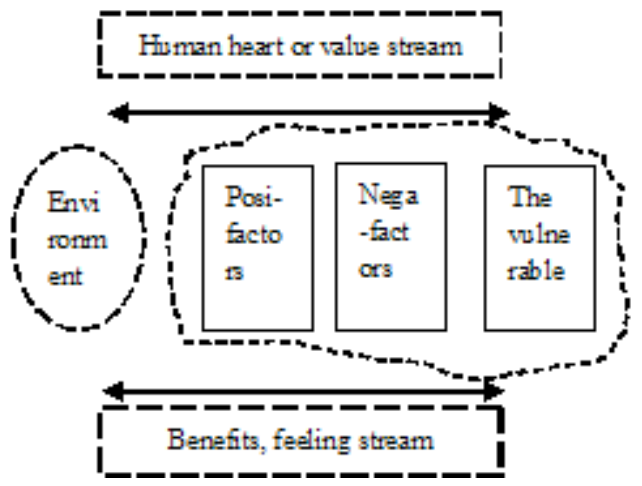

Figure 3: The dynamics upon the social system from benefits as well as value 


\section{International Journal of Science and Research (IJSR) \\ ISSN: 2319-7064}

ResearchGate Impact Factor (2018): 0.28 | SJIF (2018): 7.426

A particular social subject, individual social relationship system changes whole social situation (Fig. 3). Zhuge Liang's death caused Shu into a long-term recession. Common social subject, the change of social situation affects the change of individual social relationship system. During Chinese 10 Years Cultural Revolution, many children of CPC members severed ties with their parents the "capitalism group". For common people, forecasting the change of personal social relationship system should be combined with predicting the change of social situation. Important people have to stand the test of time, which mainly refers to whether the people with important mission can withstand the impact, whether they would betray the organization, or whether the "factors" would mutate when big events occur. When social contradictions happen, the vulnerable groups in the individual social relation system could first be exploited or attacked. Therefore, ancient Chinese said, "make friends carefully", poor character or low awareness "factors" may play a role for strategic destruction at critical time. "Making friends carefully" and "deploying people carefully" mainly refer to the principle for employing people in the environment of high uncertainty, and it will not oppose a common social communication of the subject.

Summing up above studies, to predict the individual social relationship system, following elements should be in hand (Fig. 3), (1) combining the long-term fluctuation of the social situation; (2) how the long-term strategy of positive explicit factors will change in the future, how does the rise or fall of the positive factor affect the whole situation of the subject; (3) how will the long-term strategy of the negative explicit factor change in the future, and how does the rise or fall of the negative explicit factor affect the whole situation of the subject; (4) when will major social changes occur, and when major social changes occur, to which direction the positive factor, the negative factor and the vulnerable group will evolve, furthermore, possible consequences upon the subject situation from factor changes; (5) in response to above changes, combined with social resources, what

$$
\begin{aligned}
& \mathrm{U}=\mathrm{U}(\mathrm{Q})+\mathrm{U}(\mathrm{g})=\mathrm{U}(\mathrm{Ph}, \mathrm{Ps}, \mathrm{V}, \mathrm{S}, \mathrm{M}, \mathrm{Pr}, \mathrm{O}, \bar{\zeta}, \sigma, \mathrm{t})+\mathrm{U}(\mathrm{g}) \\
& \mathrm{W}=\mathrm{W}(\mathrm{Q})+\mathrm{g}=\mathrm{W}(\mathrm{Ph}, \mathrm{Ps}, \mathrm{V}, \mathrm{S}, \mathrm{M}, \mathrm{Pr}, \mathrm{O}, \bar{\zeta}, \sigma, \mathrm{t})+\mathrm{g}
\end{aligned}
$$

The seven qualities of individual affect each other, and their attribute or change will affect the fluctuation of long-term development curve. According to their study, common people after 30 years old will reach the first peak of their life (Fig. 4). The difference of life career and the significant fluctuation of personal development curve occur between 30 and 45 years old. The development of this period plays a decisive role in the development of the whole life. In this time period, the fluctuation or change of personal development curve is caused by the following reasons: (1) the conflict of values or the difference of values, e.g., the inefficiency or failure of personal value management, (2) the failure of personal mental health and physical health management (Fig.3); (3) the inefficiency of personal ability upgrading; (4) the obsessing from social disease; (5) other uncontrollable external shocks, such as war, natural disaster, etc. measures should be taken by the subject to positive factors, negative factors and vulnerable group. Sons have to reckon situation after their fathers' vital change. Older fathers have to think about strategies in case a prosperous son suffering a sudden setback. In China, officials should think about what to do if the most important backers fall. Above studies, still does not run beyond the long-term vision and big-picture thinking.

Usually, the social environment change interacts with individual social relationship system, the strength of the bilateral interaction depends upon the correlation degree between the environmental change and the individual social relationship system. The social environment stable, the weight of the analysis and prediction upon the individual social relationship system will hike. The social environment unstable, the analysis and prediction upon the social environment will go up. Under the severe situation of Chinese Cultural Revolution, the most fortified relationship could hardly withstand the impact, and many fathers and sons turned against their eyes. In this case, it is more important to analyze and study the social environment. In current social environment, to private enterprise contract, it is more important to investigate the credit history and background of micro business partners.

\section{Personal Long Term Development Curve and Social Cycle Law}

Luo Guicheng, Tan Bin, Zheng Shiqiao (2009) studied the long-term curve of personal development. They categorized the structure of personal quality into two divisions: endogenous quality and learned quality, endogenous quality covering psychological quality, values, physiological quality. Learned quality involving personal management capacity, social capacity, professional capacity, other capabilities. In the learned quality, personal management ability is the fundamental ability, and the others are derived ability. Thus, they define the life utility function as well as the function of wealth

With data available, the econometric model of (2) wealth function can be established, and a personal development prediction system based on (2) could be attained.

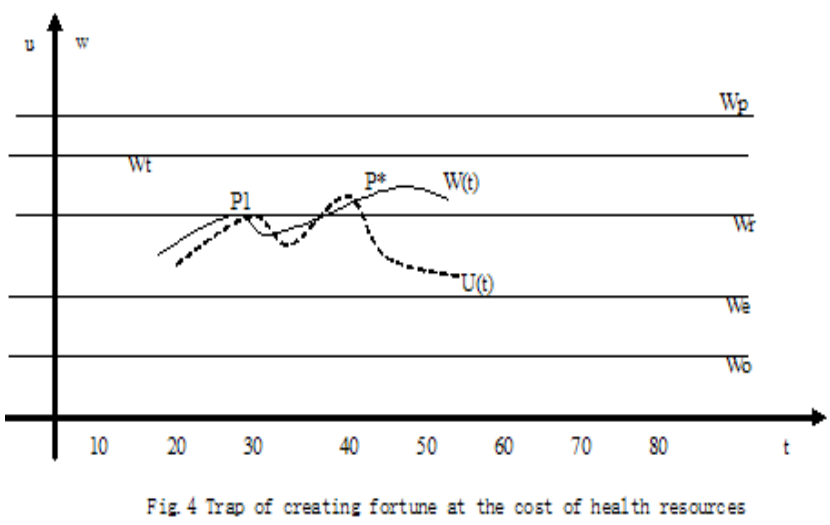

In general, in a person's life cycle, $25-45$ years old is the golden period of life development. In this period, if a major 


\section{International Journal of Science and Research (IJSR) \\ ISSN: 2319-7064}

ResearchGate Impact Factor (2018): 0.28 | SJIF (2018): 7.426

setback is caused by internal qualities, such as values, physiological quality $\mathrm{Ph}$, mental health $\mathrm{Ps}$, social ability $\mathrm{S}$, or external shocks, the long-term curve of life development will be pulled down, life development will take a bad shape. 'Indolence in young age, sadness in old time', 25-45 years old is the strategic reserve period of life. If you do not work hard in this period, the state of old age usually runs badly.

Combining the general law of individual long-term development curve with the periodic law of social development or the fluctuation of social development is of great significance to the prediction of individual development. If it is predicted that the middle-age or the old stage of the long-term development life curve would encounter some social fluctuation, or the elderly may encounter a relatively large scale war or turmoil, the subject could take preventive measures timely to avoid the risk. As a hindsight like Chinese sage Zhuge Liang, a Syrian civilian who predicted a massive war in Syria after 2012, could escape a major catastrophe by fleeing to Western Europe ahead of time.

\section{Personal capacity forecasting, project forecasting and personal development forecasting system}

Environmental prediction, personal social relationship system prediction and individual capacity prediction can be sorted into conventional management prediction and project prediction. The simplest and most effective way to predict the individual ability upon a specific project is to simulate, 'a mule or a horse, pull out for a try'. In order to improve the teaching effect, teachers undergo a try before lecture; Chinese students implement simulated tests before they have a major examination; and college pupils have a real practice in enterprises on the eve of their employment. Simulation is a good method to predict individual ability upon specific projects. Qualitative evaluation and the method of interview test have lower costs, but would be less effective.

Simulation can not completely replace the real circumstance, there are significant differences between the energy sets of both, such as the psychological state of each part, the condition of geographical location, the weather, the actual resource input. The simulation result are satisfactory, while the result of actual combat may be different.

All previous studies focused on trend forecasting, while non-professionals are more concerned with project forecasting. Project prediction is the concrete application of environmental prediction and subject capacity prediction. Generally, the larger the time span, the more difficult to predict. If the social environment stable, and no internal control over the examination results, it is easy to predict high school students' entrance examination into university, college students' entrance examination for postgraduate programs, social youth's examination for actuary programs. The result of several simulation tests could generally show the future. In addition to an excellent forecast upon macro political environment, subject capacity, it is necessary to make a thorough analysis upon the object of investment. The subject wants to invest in Alibaba, Haier, Lenovo, Baidu, Apple and Facebook, besides making a good forecast upon the international economy trend, a detailed study of the relevant companies and a relatively clear judgment on what may happen in next few years must be made, also the investment risk assessment. If it is a war between nations, the results of future wars can also be calculated by using real data in large computer simulation systems, although there may be errors in this result.

For personal development, professionals make annual forecasts, three-year prediction, five-year prediction, and ten-year prediction to serve the annual plan, the triennium plan, the five-year plan, the ten-year plan. Taking a university teacher as an example, he can combine function (2) to build a simple personal development forecasting system (Table 2).

Table 2, in the predicting system, the personal quality, the change of personal social relationship system is relatively easy to predict. Social resistance coefficient $\xi$, according to research by Luo Guicheng, Tan Bin, Zheng Shiqiao, is usually replaced by social corruption rate. In different social environments, social stability, social resistance coefficient $\xi$ and social random impact $\sigma$ are different. North Korea, Middle East, countries along the border of NATO and Russia, Chinese Taiwan, South China Sea countries, are more uncertain; China, Russia, India, Brazil and South Africa, these BRICS countries are slightly more stable; currently, developed countries such as U.S. and Western Europe have lower social risks overall. Natural disasters are more difficult to predict. The coefficient of social resistance $\xi$ varies along different subjects. The development costs paid by people suffering from social diseases are much higher than those of normal people. People infected with social disease will confront the difficulty of carrying out economy construction while feudal rascals secretly create sabotage. After making the function (2) into an econometric model, the results of the prediction system in Table 2.3.2 will be more specific, but not necessarily more accurate.

It is very important that the personal social relationship system be listed as the influence variable for personal development prediction, because the change of the factor of personal social relationship system will generate a positive or negative effect upon personal development. Bible of Change in China has a high degree of accuracy in project prediction, those interested can try. 


\section{International Journal of Science and Research (IJSR) \\ ISSN: 2319-7064}

ResearchGate Impact Factor (2018): 0.28 | SJIF (2018): 7.426

Table 2: The development forecast system for a college teacher

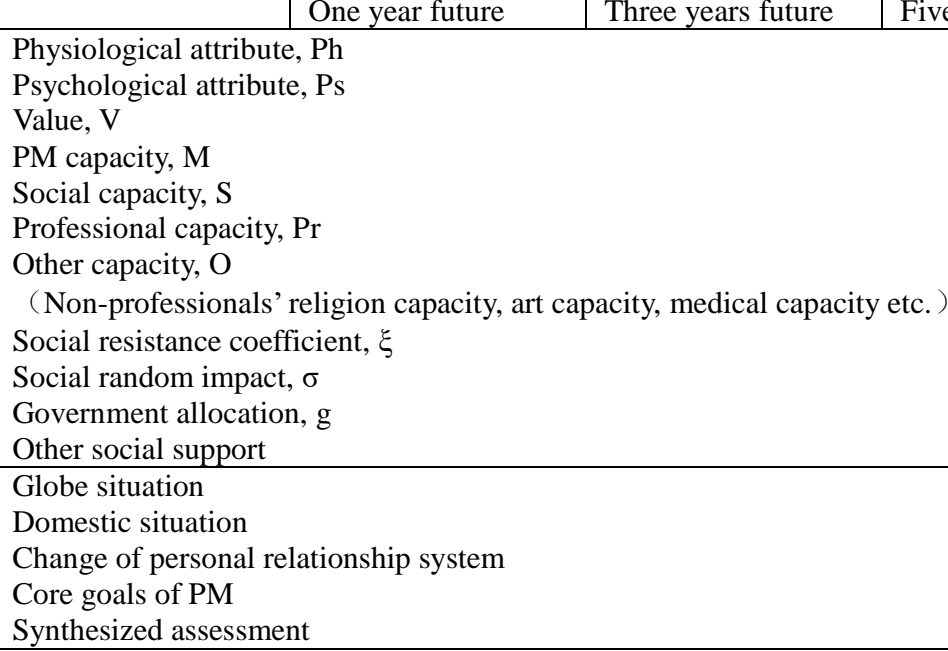

\section{History and human nature}

'Foresee one's adult at his three years old , foresee his old age at 7 years old', this assertion is too absolute, but it shows that human nature is the overall, long term variable of life development, and also illustrates the significance of personal value management to PM . If hard to grasp the future, grasp principles; if difficult to pre-view the future, try to observe people's minds. In the case of territorial disputes, if the international community coordinates fruitless, it often seeks armed force. On the path of life career, it is even more likely that a fierce character would encounter violence end, an intriguing man would be trapped in the conspiracy circle, the less likely a man with a coward inner world gets great wealthy, and the little possibility of being attacked for a kind nature. In China, it is more likely that a common figure with an uncontrolled mouth upon politics be infected with social diseases, and wealth owners are more likely to suffer attack from darkness.

Know the future by drawing lessons from history, history not only reveals human nature profoundly, but also indicates the periodic law of social system movement from time length. Up to now, the most effective instrument to renovate human nature is religion, or religious belief can effectively change the shape of the personal long-term development curve.

\section{Conclusions}

'Predict the future, more to create a future' (Xi Jinping 2015), a group leader must have this mentality. Ordinary civilians, their more important purpose of predicting the future is to prepare or prevent the future. In the application, forecasting management has two functions: creating function and preventing function. To exert the powerful function of forecasting management, the subject must observe the big field, stand upon the long-term, get deeply into people's heart, combine the prediction of environmental trend, the system of individual social relations, with the prediction of individual capacity vividly, attach importance to the principle of one whole unity for heaven, earth and human. Pay high concern to the macro atmosphere and omen information, improve the ability of strategic prediction and strategy planning, promote acute response ability on the real circumstance. Vision affects the effectiveness of management, putting aspiration upon the high and far is not empty word to professional managers.

\section{References}

[1] Hao Hongbin. Theory of War cycle and Battle Thoughts, CONMILIT, April 1998.

[2] Luo Guicheng. On Management for Personal View of Value. Pioneering With Science \& Technology Monthly, 2017 (12): 100.

[3] Luo Guicheng, Fei Ruibo, Chen Jiyin. Study On Management for Personal View on Value. www.paper.edu.cn. 2009: 1.

[4] Luo Guicheng, Luo Rundong. Analysis on Personal Social Relation System with Systematic Insights. www.paper.edu.cn. 2008 / 07: 2-3.

[5] Luo Guicheng, Luo Rundong. On Building of Personal Management, A Frontier Science. www.paper.edu.cn. 2008: 1-2.

[6] Luo Guicheng, Tan Bin, Zheng Shiqiao. Personal Quality Structure, Social Order and Long Term Curve of Personal Development. www.paper.edu.cn. 2009.

[7] Luo Guicheng, Zhu Guangyao, Ren Qun Luo. On World Optimum Population and Sustainable Development. www.paper.edu.cn. 2010: 6-7.

[8] Yan Yao-jun, Social Prediction: a Branch of Sociology Must to Be Establised. Theory and Modernization. 2003 No. 2: 46.

[9] Zhang GE. A Brief History of World War. Beijing: China Literature and History Press. 2014.02. 